\section{Breaking Tuber Dormancy in Helianthus tuberosus L. and Interspecific Hybrids of Helianthus annuus L. X Helianthus tuberosus}

\author{
Michael Kantar ${ }^{1}$ and Kevin Betts \\ Agronomy and Plant Genetics, University of Minnesota, 411 Borlaug Hall, \\ 1991 Buford Circle, St. Paul, MN 55108
}

Brent S. Hulke

USDA-ARS Northern Crops Science Laboratory, Agricultural Research Service, U.S. Department of Agriculture, 1605 Albrecht Boulevard, Fargo, ND 58102-2765

\author{
Robert M. Stupar and Donald Wyse \\ Agronomy and Plant Genetics, University of Minnesota, 411 Borlaug Hall, \\ 1991 Buford Circle, St. Paul, MN 55108
}

Additional index words. gibberellic acid, ethylene, cytokinin, cold treatment

\begin{abstract}
Tubers of Helianthus tuberosus L. are dormant after production in the late fall until the next spring. In the wild, tuber dormancy is broken after exposure to winter cold, resulting in sprouting and shoot development in the spring when conditions are favorable. The dormancy period typically limits $H$. tuberosus populations to one growth cycle per year. An efficient method for breaking tuber dormancy is needed to have an additional growth cycle per year in a breeding program, which could take place in winter in the nursery or the greenhouse allowing for increased breeding efficiency. The objective of this research was to compare chemical and cold temperature treatments for artificially breaking tuber dormancy in 12 genotypes of $H$. tuberosus and interspecific hybrids of Helianthus annuus L. $\times$ H. tuberosus. Five cold exposures $\left(2,4,6,8,10\right.$ weeks at $\left.2^{\circ} \mathrm{C}\right)$, three plant hormones (ethylene, cytokinin, and gibberellic acid), and one untreated control were examined. Gibberellic acid was the best chemical treatment, initiating plant growth within 6.5 to 11.5 days in the majority of genotypes tested. The best cold treatment was exposure to $2{ }^{\circ} \mathrm{C}$ for 8 weeks, where plant growth began 63.6 to 67.5 days after treatment initiation. Although longer cold treatments shortened the time to emergence while in the greenhouse, the penalty of the long cold treatment per se was too long to be useful. The gibberellic acid treatment strategy described here may not need further optimization, because it is short enough to allow for two growth cycles of $\mathrm{H}$. tuberosus per year.
\end{abstract}

Plant propagule dormancy ensures that plant growth occurs during optimal environmental conditions. Plants use environmental cues such as shortening photoperiod, colder temperatures, and mild drought to regulate growth habit. Dormancy is generally broken by consistent changes in the environment that lead to favorable growing conditions (i.e.,

Received for publication 10 Apr. 2012. Accepted for publication 1 Aug. 2012.

We thank Pedro Bezerra for help in conducting experiments, Dr. Eric Watkins for use of cold chambers, and Dr. Neil Anderson for advice concerning experimental design.

Mention of trade names or commercial products in this publication is solely for the purpose of providing specific information and does not imply recommendation or endorsement by the U.S. Department of Agriculture. USDA is an equal opportunity provider and employer.

${ }^{1}$ To whom reprint requests should be addressed; e-mailkant0063@umn.edu. a response to erratic environmental changes could lead to plant death). Dormancy is defined as the suspension of active growth in meristematic tissue (Kalberer et al., 2006). There are three general types of dormancy (Lang, 1987): endodormancy, paradormancy, and ecodormancy. Endodormancy is related to physiological factors within plant organs, paradormancy is related to physiological factors outside the affected plant organs but within the plant, and ecodormancy is related to environmental factors. Helianthus tuberosus L. is thought to be regulated by endodormancy (Kays and Nottingham, 2008). The biochemical mechanisms that affect the tuber dormancy period have been well studied in H. tuberosus and these studies have implicated an increased level of polyamines in actively growing tuber cells relative to dormant tuber cells (Bagni and Serafini-Fracassini, 1985; Kays and Nottingham, 2008; Tassoni et al., 2010).

Breaking dormancy artificially is important for propagation of plants outside of field or wild conditions. The use of cold treatments to break dormancy among different ecotypes of $H$. tuberosus was studied during the first half of the 20th century (Boswell, 1932; Steinbauer, 1932, 1939; Traub et al., 1929). H. tuberosus tubers quantify exposure to cold, and once the cold period has reached a certain length, the tubers initiate growth (Kays and Nottingham, 2008). The time required to break dormancy for H. tuberosus is dependent on ecotype and ranges between 30 and $200 \mathrm{~d}$ (Steinbauer, 1939; Traub et al., 1929). Cold acclimation temperatures between -2 and $5{ }^{\circ} \mathrm{C}$ have been recommended, because tubers rot above $5{ }^{\circ} \mathrm{C}$ and freeze below $-2{ }^{\circ} \mathrm{C}$ (Whiteman, 1957).

Various chemical treatments have also been studied with regard to breaking tuber dormancy in both Helianthus and Solanum species. In potato (Solanum tuberosum L.) tubers, ethanol caused apical bud dormancy to be broken more quickly than in untreated controls (Claassens et al., 2005). In H. tuberosus, an ethanol treatment caused apical bud dormancy to be masked (during treatment tuber cell growth occurred), but after the ethanol treatment stopped, cell growth stopped and dormancy was restored (Petel et al., 1993). 2,4-dichlorophenylacetic acid has been shown to break dormancy in cultured H. tuberosus tuber cells (Bennici et al., 1982). In potato tubers, ethylene and gibberellic acid have been implicated in both breaking dormancy and initiating growth after dormancy, but the role of these hormones has not been clearly defined (Coleman, 1998). Cytokinins have been implicated in the maintenance of dormancy in
Table 1. Genotype name, annual parent, species, and flowering time for the plant material used in this study.

\begin{tabular}{lcll}
\hline Genotype & Annual parent & \multicolumn{1}{c}{ Species } & Flower initiation \\
\hline JA 5 & None & H. tuberosus & Late \\
JA 8 & None & H. tuberosus & Late \\
JA 9 & None & H. tuberosus & Late \\
JA 213 & HA 89 & H. tuberosus $\times$ H. annuus & Early \\
CMS 201 D & CMS 89 & H. tuberosus $\times$ H. annuus & Early \\
JA 206 D & HA 89 & H. tuberosus $\times$ H. annuus & Early \\
JA 312 F & HA 434 & H. tuberosus $\times$ H. annuus & Early \\
CMS 201 C & CMS 89 & H. tuberosus $\times$ H. annuus & Intermediate \\
JA 212 I & HA 89 & H. tuberosus $\times$ H. annuus & Intermediate \\
JA 318 F & HA 434 & H. tuberosus $\times$ H. annuus & Intermediate \\
JA213 $\times$ HA 89 & HA 89 & (H. tuberosus $\times$ H. annuus $) \times$ H. annuus & Early \\
CMS2xx $\times$ HA 89 & CMS 89 & (H. tuberosus $\times$ H. annuus $) \times$ H. annuus & Early \\
\hline
\end{tabular}


potato tubers (Coleman, 1998). Because these hormones have been implicated in potato tuber dormancy, they may have similar effects on the tubers of $H$. tuberosus.

H. tuberosus has an important history as a specialty food crop. Initial breeding efforts date back to the 17 th century although the first systematic breeding program did not begin until the early 20 th century (Kays and Nottingham, 2008). The major goal of these breeding programs has been to increase tuber yield and inulin content. Inulin, the primary storage carbohydrate of $H$. tuberosus, is proposed as a source of carbohydrate that will help fight the obesity epidemic because inulin is of low caloric value and can be helpful
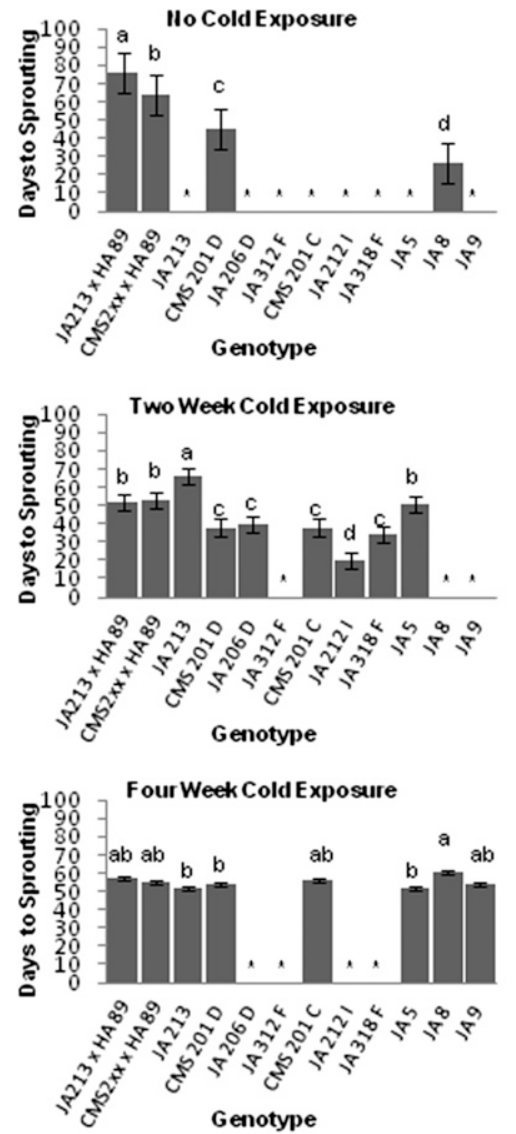
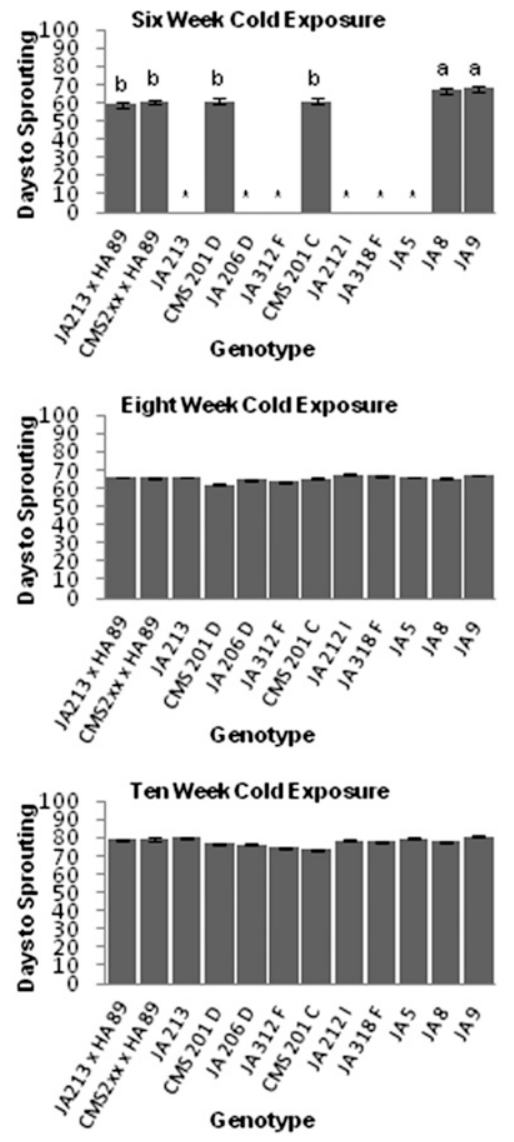

Fig. 1. Influence of $2{ }^{\circ} \mathrm{C}$ cold treatments on total days (treatment + days in greenhouse) to sprouting in nine interspecific sunflower hybrids and three H. tuberosus genotypes. Letters (a-d) above the bars indicate significantly different groups as indicated by least significant difference (LSD). An asterisk $\left(^{*}\right)$ indicates that the genotype did not germinate under this treatment.

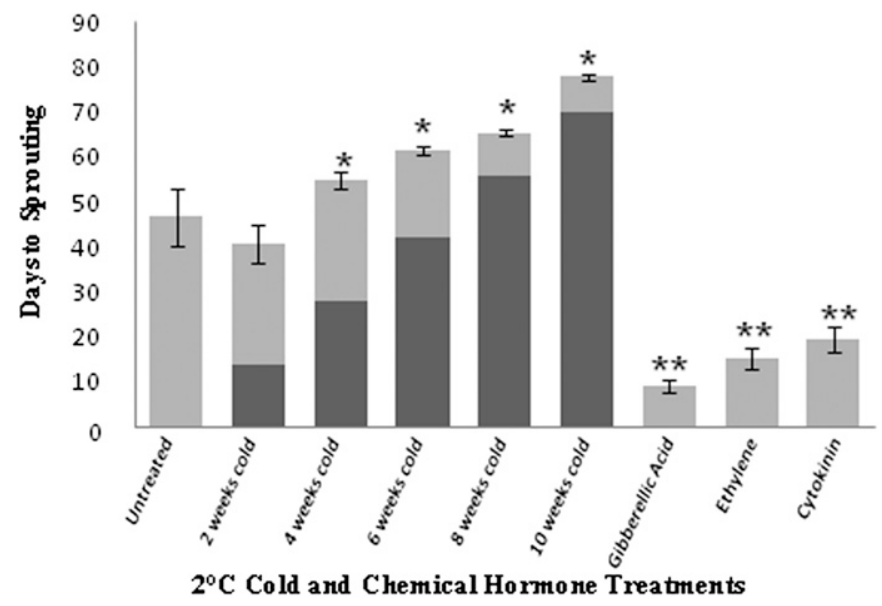

LSD am ong cold $=7.18$

LSD am onghorm one $=3.25$

Days to
sprouting after
treatment
ended

ULength of time

under

treatment

Fig. 2. Influence of cold and chemical hormone treatments on time to sprouting averaged across nine interspecific sunflower hybrids and three $H$. tuberosus genotypes. Error bars indicate the SE for each treatment. The separate cold treatment and chemical hormone treatment experiments were both compared with an untreated control where an asterisk $\left(^{*}\right)$ indicates that the treatment caused tubers to sprout in a significantly longer time than the untreated control and a double asterisk $\left({ }^{* *}\right)$ indicates that the treatment caused tubers to sprout in a significantly shorter time than the untreated control. 
populations collected and developed in 2003 by Hulke and Wyse (2008). Briefly, the initial interspecific populations were created by crossing 18 wild $H$. tuberosus parents collected from UMore Park in Rosemount, MN, to three inbred cultivated $H$. annuus lines [CMS HA89 (Miller, 1997), HA89 (released by the USDA-ARS in 1971), and HA434 (Miller et al., 2004)]. HA89 and HA434 were used as male parents and CMS HA89 was used as a female parent. The different genomic backgrounds exhibited variation in timing of floral initiation: early-season flowering (before 15 July), intermediate season (before 15 Aug.), or late season (after 15 Aug.) (Table 1). Annual parental inbreds flowered either early season or intermediate season. Tubers of all genotypes were morphologically similar and of similar size. Large tubers were selected as having been shown to have better germination (Kays and Nottingham, 2008). One tuber was planted per pot with all tubers of any given genotype being harvested from the same clone that had fully senesced and had produced viable seed.

Cold treatment. The first experiment was designed to identify the optimum duration of cold treatment needed to break tuber dormancy. The experimental design was a randomized complete block with a split plot arrangement of treatments with four replicates. The cold period duration treatments were arranged as the whole plots, whereas genotypes were arranged as the subplots. Genotypes exhibited flowering times covering the entire season in Minnesota within $H$. tuberosus (Table 1). Tubers were collected from the field in mid-Oct. 2009, planted in cone-tainers (Stuewe \& Sons Inc., Tangent, OR) in Sunshine professional growing mix ${ }^{\circledR}$ (Sun Gro, Seba Beach, Alberta, Canada), and then placed in a cold acclimation room at $2{ }^{\circ} \mathrm{C}$ with no lights in early Nov. 2009. Depth of planting was $1.25 \mathrm{~cm}$ below the soil surface. After being placed in the cold room, tubers were removed after $2,4,6,8$, and 10 weeks and placed in the greenhouse with $14 \mathrm{~h}$ daylength at $\approx 24{ }^{\circ} \mathrm{C}$. Control tubers received no cold acclimation and were placed directly into the greenhouse. All tubers were scored for number of days to sprouting after initiation of treatment. A positive score was a sprout visible above the soil surface. We did not dig up unsprouted tubers at the end of the experiment nor did we test them with a hormone to see if they were still viable. The control tubers were maintained until all of the plants from the cold treatments had flowered.

Hormone treatment. The second experiment examined breaking tuber dormancy by use of a chemical plant hormone treatment. The experimental design was a randomized complete block with three replicates in a split plot arrangement of treatment. Whole plots were hormone and subplots were genotype. Hormone treatments were chosen as representative of treatments used to break seed dormancy in several species (Biddington and Thomas, 1976; Koyuncu, 2005; Miller, 1987; Rehman and Park, 2000) and tuber dormancy in Solanum tuberosum (Coleman, 1998).

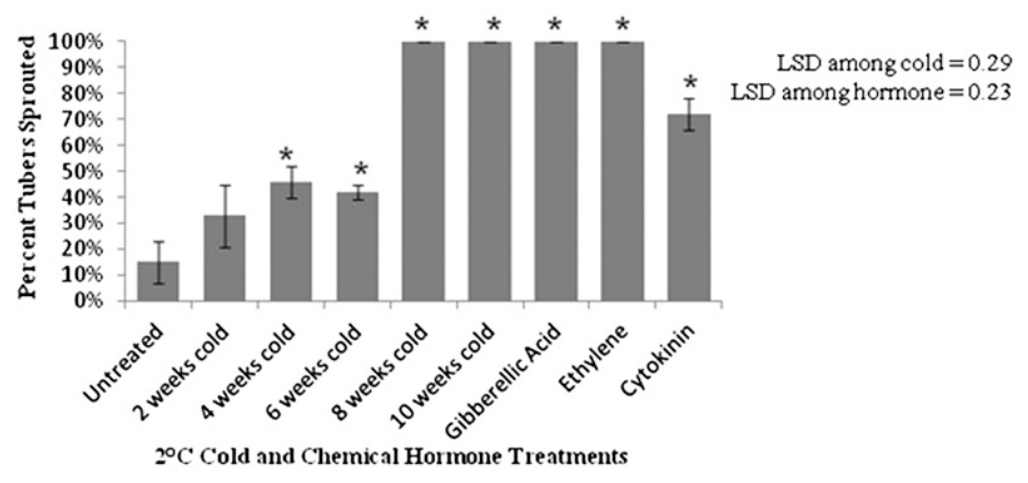

Fig. 3. Percentage of treated tubers that sprouted under the influence of cold and chemical hormone treatments across nine interspecific sunflower hybrids and three $H$. tuberosus genotypes. The separate cold treatment and chemical hormone treatment experiments were both compared with an untreated control where an asterisk $(*)$ indicates that the treatment caused significantly more tubers to sprout than the untreated control.
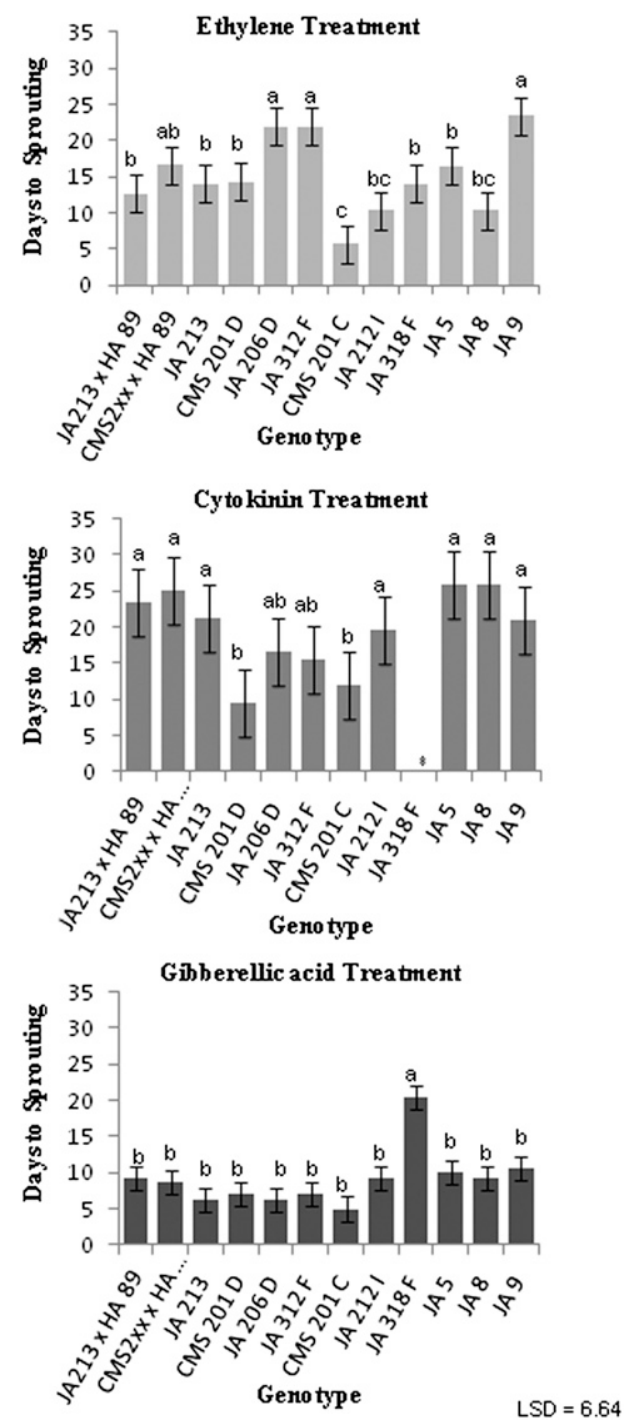

Fig. 4. Influence of hormone treatments on total days (treatment + days in greenhouse) to sprouting in genotypes in nine interspecific sunflower hybrids and three H. tuberosus genotypes. Error bars indicate the SE for each individual hormone. Letters $(\mathrm{a}-\mathrm{c})$ indicate significantly different groups as indicated by least significant difference (LSD). An asterisk $(*)$ indicates that the genotype did not germinate under this treatment.

Three hormones were evaluated: ethylene, cytokinin, and gibberellic acid. Ethylene was applied by soaking tubers overnight in a $1 \%$ aqueous ethephon solution (Proxy®; Bayer
Environmental Science, Research Triangle Park, NC). Ethephon has been used to promote preharvest ripening in fruit and has been shown to decompose to ethylene in plant 
tissue (Epstein et al., 1977). Cytokinin was applied by soaking the tubers for 90 to $120 \mathrm{~s}$ in a $2000 \mathrm{ppm}$ aqueous cytokinin solution (6-benzylamino purine; Sigma-Aldrich, St. Louis, MO). Gibberellic acid was applied by soaking tubers for 90 to $120 \mathrm{~s}$ in a $2 \%$ aqueous gibberellic acid solution (4\% ProGibb®); Valent, Memphis, TN). After treatment, the tubers were planted in $5-\mathrm{cm}$ pots in Sunshine professional growing mix ${ }^{\circledR}$ (Sun Gro), $1.25 \mathrm{~cm}$ under the soil surface, and placed in a greenhouse with $14 \mathrm{~h}$ daylength at $24^{\circ} \mathrm{C}$. All tubers were scored for days to sprouting after initiation of the hormone treatment and scored in the same way as the cold experiment.

Statistical analysis. Statistical analysis was conducted using R Statistical software package (R Development Core Team, 2008). Treatment means were separated using a Fisher's protected least significant difference. A significance level of $P \leq 0.05$ was used to determine treatment differences. Two models were tested for each treatment program: one with a linear covariate for flowering date and one without this covariate. When replicate tubers did not germinate, they were treated as missing data; however, the gibberellic acid, ethylene, 8-week and 10 -week cold treatments had no missing data.

\section{Results}

Cold treatment. The effect of cold treatment was measured as the total time from treatment initiation to tuber sprouting in the greenhouse. The ideal cold treatment would be the minimum duration treatment that breaks dormancy of all genotypes. Not all genotypes sprouted under all cold treatments (Fig. 1); most $(67 \%)$ required a pretreatment to stimulate growth. Not all genotypes sprouted in response to the shorter cold treatments (2 through 6 weeks). These data support previous research showing that tuber dormancy varies among $H$. tuberosus genotypes (Steinbauer, 1932, 1939). The 2 -week treatment produced the earliest overall emergence (Fig. 2). However, only nine of the 12 genotypes emerged after the 2-week treatment. The 8-week treatment was the shortest cold treatment under which all genotypes sprouted. This emergence, however, was not until 63.6 to $67.5 \mathrm{~d}$ after treatment initiation. However, if the time of treatment is not considered, then the genotypes sprouted in 7.6 to $11.5 \mathrm{~d}$ in response to the 8-week cold treatment. In addition, complete emergence $(100 \%)$ from all genotypes and tubers was not observed until the 8-week treatment (Figs. 1 and 3). Plant growth proceeded normally through anthesis and reproduction after all cold exposures.

Hormone treatment. All hormone treatments resulted in more rapid sprouting than the untreated control (Fig. 2). Gibberellic acid treatment resulted in significantly faster tuber sprouting than ethylene treatment, which caused significantly faster tuber sprouting than cytokinin treatment (Fig. 2). All genotypes sprouted under the ethylene and gibberellic acid treatment, which initiated growth within 9.8 to $20.5 \mathrm{~d}$ and 6.5 to $11.5 \mathrm{~d}$, respectively.
The cytokinin treatment caused tubers to sprout in 14 to $25.2 \mathrm{~d}$; however, not all genotypes sprouted (JA 318F failed to sprout) (Fig. 4).

There was a genotype-by-hormone interaction indicating that genotypes responded differently to plant hormones. The interaction is mostly the result of rankwise differences between the ethylene and the cytokinin treatment, except in the case of JA318F in which the interaction occurred among all three treatments. JA318F was the only genotype that did not sprout earliest under the gibberellic acid treatment (Fig. 4). The percentage of $H$. tuberosus genome in the genotypes did not seem to have an effect on response to chemical hormone, because some of the earliest and latest plants to emerge were interspecific hybrids (Fig. 4). Plant growth was somewhat atypical after each of the hormone treatments because multiple shoots were generated from a single tuber. However, if plants were trimmed to a single shoot per tuber, plant growth appeared to proceed normally through anthesis and reproduction.

Flowering time and dormancy. When genotypes were grouped by flowering time during the growing season (early, intermediate, or late season), there was no difference in how they developed after cold or hormone treatment. There was no interaction between hormone treatment or cold treatment and flowering time. The flowering time covariate was not significant with $P=0.17$ and $P=0.15$ for cold and hormone treatments, respectively.

\section{Discussion}

The goal of this project was to determine the fastest method for breaking dormancy in $H$. tuberosus tubers. Ideally, an optimized method would allow researchers to evaluate or increase materials under greenhouse or winter nursery conditions and have new mature tubers ready to induce and plant for the next growing season (i.e., allowing for two growth cycles per year rather than one) (Fig. 5). Bearing this goal in mind, we chose to evaluate the treatments based on the total amount of time from treatment initiation to plant emergence in the greenhouse (Fig. 2). By this measure, all three chemical treatments outperformed even the best cold treatment. Although longer cold treatments shortened the time to emergence in the greenhouse, the penalty of the long cold treatment per se was too great to complete two growth cycles per year (Fig. 5). Moreover, the ethylene and gibberellic acid chemical treatments induced sprouting among all genotypes and tubers tested, whereas only the longest cold durations (8- and 10-week treatment) were able to break dormancy in all genotypes and tubers tested (Fig. 3).

Among the chemical treatments, the most effective plant hormone for breaking dormancy was gibberellic acid. Nearly every genotype tested exhibited the most rapid sprouting under the gibberellic acid treatment, with the exception of JA $318 \mathrm{~F}$, which sprouted most rapidly in response to ethylene. It remains an interesting question whether altering the dosage of any of these hormonal treatments may shorten the time to break dormancy below that of our current gibberellic acid treatment (as a $2 \%$ aqueous solution). However, that question may be irrelevant because the gibberellic acid treatment broke tuber dormancy in less than 3 weeks and allowed us to achieve two full growth cycles on all genotypes in 2010 to 2011 . The gibberellic acid treatment accomplishes the goal of getting two full growth cycles per year from H. tuberosus and interspecific Helianthus hybrids.

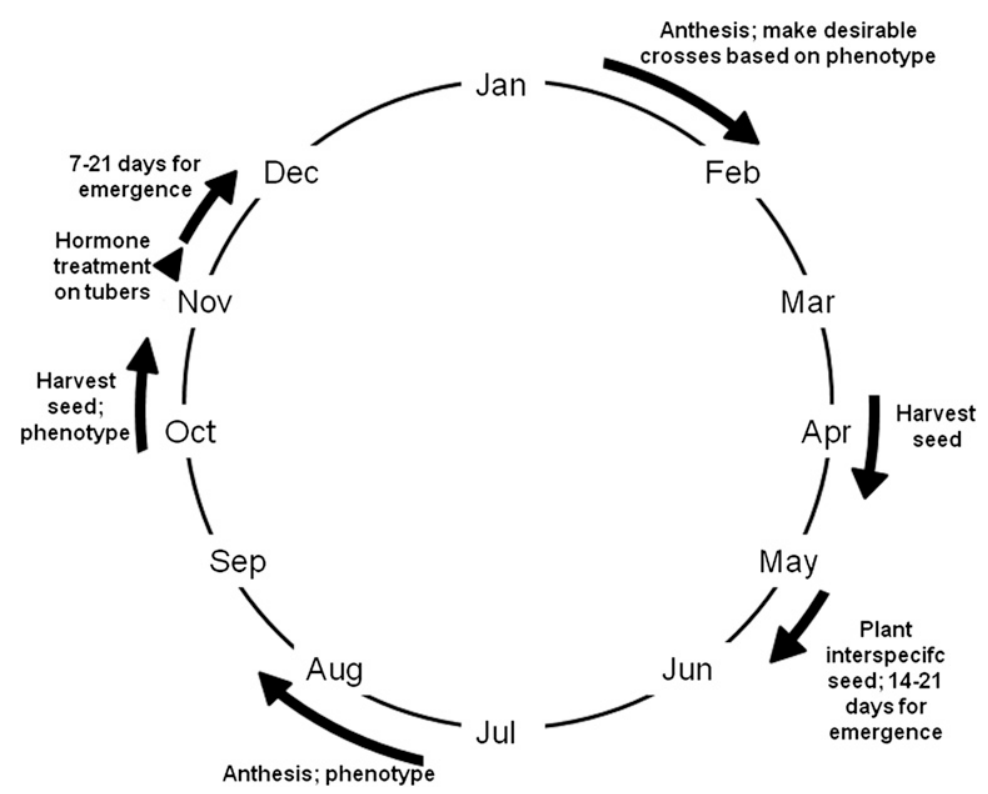

Fig. 5. Potential breeding scheme to get two generations per year of H. tuberosus or H. tuberosus $\times$ H. annuus interspecific hybrids. Length of arrows indicates the approximate amount of time an activity will take. 


\section{Literature Cited}

Bagni, N. and D. Serafini-Fracassini. 1985. Involvement of polyamines in the mechanism of break of dormancy in Helianthus tuberosus. Bull. Soc. Bot. Fr. Actual Bot. 132:119-125.

Bennici, A., P.G. Cionini, D. Gennai, and G. Cionini. 1982. Cell cycle in Helianthus tuberosus tuber tissue in relation to dormancy. Protoplasma 112: 133-137.

Biddington, N.L. and T.H. Thomas. 1976. Influence of different cytokinins on the germination of lettuce (Lactuca sativa) and celery (Apium graveolens) seeds. Physiol. Plant. 37:12-16.

Boswell, V.R. 1932. Length of rest period of the tuber of Jerusalem artichoke (Helianthus Tuberosus L.). Proc. Amer. Soc. Hort. Sci. 28:297-300.

Charlet, L.D. and G.J. Brewer. 1995. Resistance of native sunflower (Asterales:Asteraceae) to the banded sunflower moth (Lepidoptera: Cochylidae). Entomological Society of America 24:1224-1228.

Claassens, M.M.J., J. Verhees, L.H.W. van der Plas, A.R. van der Krol, and D. Vreugdenhil. 2005. Ethanol breaks dormancy of the potato tuber apical bud. J. Expt. Bot. 56:2515-2525.

Coleman, W.K. 1998. Carbon dioxide, oxygen and ethylene effects on potato tuber dormancy release and sprout growth. Ann. Bot. (Lond.) 82: 21-27.

DeHaan, L.R., D.L. Van Tassel, and T.S. Cox. 2005. Perennial grain crops: A synthesis of ecology and plant breeding. Renewable Agriculture and Food Systems 20:5-14.

Epstein, E., I. Klein, and S. Lavee. 1977. The fate of 1,2,- 4C-(chloroethyl) phosphonic acid (ethephon) in olive (Olea europea L.). Physiol. Plant. 39:33-37.

Hu, F.Y, D.Y. Tao, E. Sacks, B.Y. Fu, P. Xu, J. Li, Y. Yang, K. McNally, G.S. Khush, A.H. Paterson, and Z.K. Li. C 2003. Convergent evolution of perenniality in rice and sorghum. PNAS 100: 4050-4054.

Hulke, B. and D. Wyse. 2008. Using interspecific hybrids with $H$. annuus $\mathrm{L}$. 17th International Sunflower Conference, Cordoba, Spain. p. 729 734.

Jan, C.C. and G.J. Seiler. 2007. Sunflower, p. 103 166. In: Singh, R.J. (ed.). Resources, chromosome engineering, and crop improvement series: Oilseed crops. Vol. 4. CRC Press, Boca Raton, FL.

Kalberer, S.R., M. Wisniewski, and R. Arora. 2006. Deacclimation and reacclimation of cold-hardy plants: Current understanding and emerging concepts. Plant Sci. 171:3-16.

Kays, S.J. and S.F. Nottingham. 2008. Biology and chemistry of Jerusalem artichoke Helianthus tuberosus L. CRC Press, Boca Raton, FL.

Koyuncu, F. 2005. Breaking seed dormancy in black mulberry (Morus nigra L.) by cold stratification and exogenous application of gibberellic acid. Acta Biol. Crac. Bot. 47:23-26.

Lang, G.A. 1987. Dormancy: A new universal terminology. HortScience 22:817-820.

Miller, J.F. 1987. Sunflower, p. 626-668. In: Fehr, W.R. (ed.). Principles of cultivar development. Vol. 2. Macmillan, New York, NY.

Miller, J.F. 1997. Registration of cmsHA 89 (PEF1) cytoplasmic male-sterile, RPEF1 restorer, and two nuclear male-sterile (NMS 373 and 377) sunflower genetic stocks. Crop Sci. 37:1984.

Miller, J.F. and T.J. Gulya. 1987. Inheritance of resistance to race 3 downy mildew in sunflower. Crop Sci. 27:210-212.

Miller, J.F., T.J. Gulya, and B.A. Vick. 2004. Registration of two maintainer (HA 434 and HA 435) and three restorer (RHA 436 to RHA 438) high oleic oilseed sunflower germplasms. Crop Sci. 44:1034-1035.

Petel, G., P. Candelier, and M. Gendraud. 1993. Effect of ethanol of filiate tubers of Jerusalem artichoke: A new tool to study tuber dormancy. Plant Physiol. Biochem. 31:67-71.

R Development Core Team. 2008. R: A Language and Environment for Statistical Computing. R Foundation for Statistical Computing, Vienna, Austria. $<$ http://www.R-project.org $>$.

Rehman, S. and I.H. Park. 2000. Effect of scarification, GA and chilling on the germination of goldenrain-tree (Koelreuteria paniculata Laxm.) seeds. Sci. Hort. 85:319-324.

Sacks, E.J., J.P. Roxas, and M.T. Cruz. 2003. Developing perennial upland rice I: Field performance of Oryza sativa| O. rufipogon F1, F4 and BC1F4 progeny. Crop Sci. 43:120-128.

Steinbauer, C.E. 1932. Effects of temperature and humidity upon length of rest period of tubers of Jerusalem artichoke (Helianthus tuberosus L.). Proc. Amer. Soc. Hort. Sci. 29: 403-408.

Steinbauer, C.E. 1939. Physiological studies of Jerusalem artichoke tubers with special reference to the rest period, USDA technical bulletin 657. USDA, Washington, DC.

Tassoni, A., N. Bagni, M. Ferri, M. Franceschetti, A. Khomutov, M.P. Marques, S.M. Fiuza, A.R. Simonian, and D. Serafini-Fracassini. 2010. Helianthus tuberosus and polyamine research: Past and recent applications of a classical growth model. Plant Physiol. Biochem. 48:496-505.

Traub, H.P., C.J. Thor, J.J. Willaman, and R. Oliver 1929. Storage of truck crops: The girasole, Helianthus tuberosus. Plant Physiol. 4:123124.

Wang, R., S. Farrona, C. Vincent, A. Joecker, H. Schoof, F. Turck, C. Alonso-Blanco, G. Coupland, and M.C. Albani. 2009. PEP1 regulates perennial flowering in Arabis alpine. Nature 459:423-427.

Whiteman, T.M. 1957. Freezing points of fruits, vegetables, and florist stocks, USDA MKt. Res. Reprod. 196:32. 